\title{
Energy return on investment, energy payback time, and greenhouse gas emissions of coal seam gas (CSG) production in China: a case of the Fanzhuang CSG project
}

\author{
Zhao-Yang Kong ${ }^{1} \cdot \mathrm{Xiu}^{-C h e n g} \mathrm{Dong}^{1} \cdot \mathrm{Xi} \mathrm{Lu}^{2} \cdot \mathrm{Xin} \mathrm{Wan}^{3}$
}

Received: 9 January 2017 / Published online: 14 December 2017

(C) The Author(s) 2017. This article is an open access publication

\begin{abstract}
The studies and development of coal seam gas (CSG) have been conducted for more than 30 years in China, but few of China's CSG projects have achieved large-scale commercial success; faced with the boom of shale gas, some investors are beginning to lose patience and confidence in CSG. China currently faces the following question: Should the government continue to vigorously support the development of the CSG industry? To provide a reference for policy makers and investors, this paper calculates the EROI ${ }_{\text {stnd }}$ [a standardized energy return on investment (EROI) method], EROI ${ }_{\text {ide }}$ (the maximum theoretical EROI), $\mathrm{EROI}_{3, \mathrm{i}}$ (EROI considering the energy investment in transport), and $\mathrm{EROI}_{3,1+\mathrm{e}}$ (EROI with environmental inputs) of a single vertical CSG well in the Fanzhuang CSG project in the Qinshui Basin. The energy payback time (EPT) and the greenhouse gas (GHG) emissions of the CSG systems are also calculated. The results show that over a 15-year lifetime, $\mathrm{EROI}_{\text {stnd }}, \mathrm{EROI}_{\text {ide }}, \mathrm{EROI}_{3,1}$, and $\mathrm{EROI}_{3,1+\mathrm{e}}$ are expected to deliver EROIs of approximately 11:1, 20:1, 7:1, and 6:1, respectively. The EPT within different boundaries is no more than 2 years, and the life-cycle GHG emissions are approximately 18.8 million $\mathrm{kg} \mathrm{CO}_{2}$ equivalent. The relatively high EROI and short EPT indicate that the government should take more positive measures to promote the development of the CSG industry.
\end{abstract}

Keywords Coal seam gas · EROI · Energy payback time · Greenhouse gas emissions · Global warming potential · China

\section{Introduction}

The past decade has seen a dramatic increase in unconventional gas production worldwide (Tait et al. 2013). Unconventional natural gas differs from conventional natural gas in that the latter is trapped in natural pores or fractures in sedimentary layers, while the former can also be adsorbed to the sediment itself. Coal seam gas (CSG),

Edited by Xiu-Qin Zhu

Xiu-Cheng Dong

dongxiucheng@cup.edu.cn

1 School of Business Administration, China University of Petroleum (Beijing), Beijing 102249, China

2 School of Environment and State Key Joint Laboratory of Environment Simulation and Pollution Control, Tsinghua University, Beijing 100084, China

3 School of Economics and Management, Beijing University of Chemical Technology, Beijing 100029, China which is also known as coalbed methane, is a type of unconventional natural gas that consists of natural gas that is extracted from low- to high-rank coal beds (Luo et al. 2011; Millar et al. 2016). The CSG is being extracted in several countries, including the USA, Australia, China, Canada, and India. America is the world's largest CSG producer, and its CSG production was approximately 40 billion cubic metres (bcm) in 2014 (Luo et al. 2011; Millar et al. 2016).

In the 1950s, CSG was viewed as a dangerous gas for coal mining rather than as an important potential clean energy resource (Tan et al. 2011). Most CSG was blown into the atmosphere via air ventilation; only a small portion of it was used for cooking and heating on-site at some coal mines (Yang 2009). In the late 1980s, the American CSG industry successfully achieved commercial production and expanded rapidly, which prompted China to consider the viability of a large-scale CSG industry. Since then, the Chinese government has aggressively promoted the development of the CSG industry (Luo et al. 2011). The 
Chinese government released a number of important policies on CSG recovery and utilization, such as "A Notice on Subsidies to CSG Capture and Utilization", published by the Ministry of Finance of China in April 2007 (Yang 2009). China has also actively received aid from the international community. For example, international organizations, including the United Nations Development Programme (UNDP) and the Global Environment Facility (GEF), financed the first CSG surface pre-drainage and underground directional drilling demonstration project, and in 1992, the United States Environmental Protection Agency (USEPA) provided China with 12 million dollars to promote the evaluation of CSG resources (Luo et al. 2011).

Although China has researched and developed CSG for more than 30 years, single-well production is still too low, and most of China's CSG projects are still in the exploration and pilot test phases; few have attained large-scale commercial success, which has led some investors to lose patience and confidence (Luo 2013). CSG production in China was 3 bcm in 2014 (Qing 2016), which accounted for approximately $2.2 \%$ of China's total natural gas production, which was less than in the USA (5.5\%) (Bai and Zhang 2015), whose CSG resource base is smaller than that of China. Due to the success of US shale gas, China has paid more attention to developing shale gas in recent years (Luo 2013). In fact, CSG development could have been marginalized, neglected, and even abandoned (Bai and Zhang 2015; Mu et al. 2015; Qing 2016). Thus, it is evident that China is facing a dilemma-should the government continue to vigorously support the development of the CSG industry?

To answer this question, most studies have utilized the common strategy of performing conventional techno-economic analyses (Kong et al. 2015a), such as the net present value method (Luo et al. 2011), to analyse the economics of CSG production. Energy return on investment (EROI) is a useful measure of the quality of various fuels (Hall et al. 2014). However, peer-reviewed literature has paid only minimal attention to the EROI of CSG, possibly as a result of the limited available information in the public domain. To our knowledge, only one study (Sun 2015) has estimated the EROI of CSG. However, Sun did not calculate the $\mathrm{EROI}_{\text {stnd }}$ (a standardized EROI) or EROI ide $_{\text {(the max- }}$

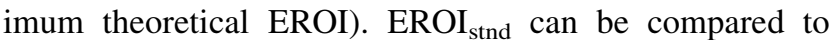
other studies, and $\mathrm{EROI}_{\text {ide }}$ can be used to estimate the potential for EROI improvement. In addition, Sun (2015) did not consider the potential impacts of the energy inputs for controlling environmental pollution on the EROI. Several recent studies (Lave and Lutz 2014) have determined that when production, transportation, and fugitive emissions are included, the life-cycle greenhouse gas (GHG) emissions from CSG are similar to those of coal
(Clark et al. 2011). This view has been widely quoted in the media and political debates (Manning 2012; Turton 2015). Therefore, it is necessary to quantify these environmental impacts and translate them into energy equivalents.

Two main types of drilling technologies have been used with CSG: conventional vertical well technology and multi-branch horizontal well technology (Wang et al. 2004; Shen 2005). Vertical wells are the more mature technology and are widely used in China (Qiao et al. 2008); they account for more than $95 \%$ of all CSG wells (Luo et al. 2009). Vertical wells are widely used in the Shanxi Qinshui Basin and have resulted in a set of drilling techniques that are appropriate for the geological characteristics of highrank coal reservoirs in this area, including near- (under-) balanced vertical drilling and cased hole completions (Luo et al. 2009). To provide valuable policy insights for policy makers, this paper seeks to systematically analyse the EROI of a single vertical well in the Fanzhuang CSG project in the Qinshui Basin, which was the first large-scale CSG demonstration project in China (Tao et al. 2015). One of the advantages of this paper is analysing the EROI ${ }_{\text {stnd }}$, $\mathrm{EROI}_{\text {ide }}, \mathrm{EROI}_{3, \mathrm{i}}(\mathrm{EROI}$ considering energy investment in transport), and $\mathrm{EROI}_{3,1+\mathrm{e}}$ (EROI with environmental inputs), which is of primary importance as it allows a broad estimation of CSG's current net energy efficiency, the future improvement potential, and environmental impacts. The energy payback time (EPT) and the GHG emissions are also calculated.

\section{Methods}

This section introduces the methods for calculating the EROI, EPT, and GHG emissions.

\section{1 $\mathrm{EROI}_{\text {stnd, }} \mathrm{EROI}_{\text {ide, }} \mathrm{EROI}_{3, \mathrm{i},}$ and $\mathrm{EROI}_{3, \mathrm{i}+\mathrm{e}}$}

The basic formula for the EROI is as follows (Hall et al. 2014):

EROI $=\frac{\text { Energy returned (outputs) }}{\text { Energy required (inputs) }}$

In previous studies, the EROI results were different even for similar fuels (Hall et al. 2014), which is mostly the result of the direct and indirect energy inputs associated with energy production that are included in the EROI calculations, such as the boundaries of the denominator. To reduce these differences, Murphy et al. (2011) proposed a "standard protocol" for calculating EROI based on categorizing the various types of published EROI analyses in Table 1 (Cleveland and O'Connor 2011), which allows researchers to state which EROI they refer to in their studies. Because most EROI studies consider both direct 
Table 1 Two-dimensional framework for EROI analysis

\begin{tabular}{llll}
\hline Levels for energy inputs & \multicolumn{2}{l}{ Boundary for energy } & \\
\cline { 2 - 4 } & 1. Extraction & 2. Processing & 3. End-Use \\
\hline Direct energy and material inputs & $\mathrm{EROI}_{1, \mathrm{~d}}$ & $\mathrm{EROI}_{2, \mathrm{~d}}$ & $\mathrm{EROI}_{3, \mathrm{~d}}$ \\
Indirect energy and material inputs & $\mathrm{EROI}_{\text {stnd }}$ & $\mathrm{EROI}_{2, \mathrm{i}}$ & $\mathrm{EROI}_{3, \mathrm{i}}$ \\
Indirect labour consumption & $\mathrm{EROI}_{1, \mathrm{lab}}$ & $\mathrm{EROI}_{2, \mathrm{lab}}$ & $\mathrm{EROI}_{3, \text { lab }}$ \\
Auxiliary services consumption & $\mathrm{EROI}_{1, \mathrm{aux}}$ & $\mathrm{EROI}_{2, \mathrm{aux}}$ & $\mathrm{EROI}_{3, \mathrm{aux}}$ \\
Environmental & $\mathrm{EROI}_{1, \mathrm{env}}$ & $\mathrm{EROI}_{2, \mathrm{env}}$ & $\mathrm{EROI}_{3, \text { env }}$ \\
\hline
\end{tabular}

and indirect energy and material inputs, Murphy et al. (2011) defined this boundary to be the standard EROI $\left(\mathrm{EROI}_{\text {stnd }}\right)$.

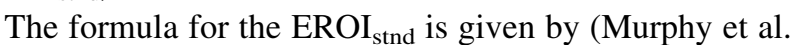
2011):

$\mathrm{EROI}_{\text {stnd }}=\frac{E_{\mathrm{o}}}{E_{\mathrm{d}}+M_{\mathrm{i}} \times E_{\mathrm{ins}}}$

where $E_{\mathrm{o}}$ is the total energy output, $E_{\mathrm{d}}$ represents the total input of different fuels, $M_{\mathrm{i}}$ is the indirect inputs in monetary terms, and $E_{\text {ins }}$ expresses the energy intensity of a dollar input.

The ideal EROI concept, which is also known as

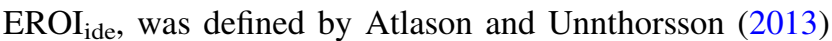
as the ratio of the theoretical maximum output from a given system to the inputs within the EROI ${ }_{\text {stnd }}$ boundaries, which indicates the potential for EROI improvement. EROI ${ }_{\text {ide }}$ can be calculated as follows (Atlason and Unnthorsson 2014a):

$\mathrm{EROI}_{\mathrm{ide}}=\frac{E_{\mathrm{ide}}}{E_{\mathrm{d}}+M_{\mathrm{i}} \times E_{\mathrm{ins}}}$

where $E_{\text {ide }}$ is the theoretical maximum output at the wellhead by omitting energy losses, which is theoretically unachievable but represents an upper boundary.

$\mathrm{EROI}_{3, \mathrm{i}}$ includes the same parameters as $\mathrm{EROI}_{\text {stnd }}$ but also includes the delivery of the energy to the consumer (Atlason and Unnthorsson 2014b). We emphasize that after long-distance transport, oil and coal remain nearly unchanged, while gas (liquefied natural gas (LNG) or pipeline gas) will suffer losses (Lin et al. 2010). Therefore, when calculating the $\mathrm{EROI}_{3, \mathrm{i}}$, it is necessary to exclude the losses during transport from the total energy outputs. The generalized EROI equation for $\mathrm{EROI}_{3,1}$ is (Kong et al. 2016a):

$\operatorname{EROI}_{3, \mathrm{i}}=\frac{E_{\mathrm{o}}-L_{\mathrm{t}}}{E_{\mathrm{e}}+E_{\mathrm{t}}}$

where $L_{\mathrm{t}}$ refers to the gas losses during transportation, and $E_{\mathrm{e}}$ and $E_{\mathrm{t}}$ refer to the energy inputs during extraction and transportation, respectively.

The equation for $\mathrm{EROI}_{3, \mathrm{i}+\mathrm{e}}$ is similar to that of $\mathrm{EROI}_{3,1}$, with the only difference being that the latter includes only direct and indirect energy inputs, while the former additionally includes the environmental inputs from energy extraction to utilization.

In this paper, two EROI methods (namely, Method A and Method B) are used to calculate $\mathrm{EROI}_{\text {stnd }}, \mathrm{EROI}_{\mathrm{ide}}$, $\mathrm{EROI}_{3,1}$, and $\mathrm{EROI}_{3,1+\mathrm{e}}$.

Method A: the EROI is equal to the cumulative energy outputs divided by the cumulative energy inputs:

$\mathrm{EROI}=\frac{\sum_{t=1}^{t} E_{O, t}}{E_{I, 0}+\sum_{t=1}^{t} E_{I, t}}$

where $E_{O, t}$ is the energy output over year $t, E_{I, 0}$ is the initial construction energy, including embodied energy, within the construction materials, and $E_{I, \mathrm{t}}$ is the energy used for maintenance and operation over year $t$.

Method B: the EROI is equal to the annual energy outputs divided by the annual energy inputs:

$\mathrm{EROI}=\frac{E_{O, t}}{E_{I, 0} / T+E_{I, t}}$

where $T$ is the expected lifetime of the plant.

Method A has been most widely used by researchers to calculate the EROI of a project or a well (Aucott and Melillo 2013; Dale et al. 2013). Using Method A, we can obtain the total EROI of a well because all of the energy inputs are considered, while the change in EROI caused by the depletion of the well (as production increases in a well, more energy is necessary for maintenance and operation to extract the same gas) cannot be observed as easily and clearly. Method B assumes that the energy input for construction in the energy year is the same, meaning that Eq. (6) mainly expresses the impact of the year-by-year change in energy used for maintenance and operation for EROI. Several studies have used Method B (Hu et al. 2011; $\mathrm{Xu}$ et al. 2014). For example, the EROI results of $\mathrm{Hu}$ et al. (2011) clearly show that the EROI of the Daqing oilfield, which is the largest oilfield in China, declined continuously from 10:1 in 2001 to $6: 1$ in 2009. Hu et al. (2011) found that the depletion of the oilfield was the main reason for the declining EROI.

The reason is principally that as fields age they require energy-intensive techniques, such as water and polymer injection under substantial pressure...... 
Also, the reason for the decline in EROI is that while the production of Daqing decreased slowly, the investment of funds and energy increased almost linearly.

In the past, researchers have used either Method A or Method B to calculate EROI. Here, given that Method A and Method B have their own advantages, both of them are used in the $\mathrm{EROI}_{\text {stnd }}, \mathrm{EROI}_{\mathrm{ide}}, \mathrm{EROI}_{3,1}$, and $\mathrm{EROI}_{3,1+\mathrm{e}}$ scenarios.

\subsection{Energy payback time (EPT)}

The EPT, which is also called the energetic amortization time, is the time at which the returned energy equals the energy invested; it indicates when a given plant starts to deliver surplus energy (Weißbach et al. 2013) and is therefore an important parameter for evaluating the sustainability of any energy-producing technology (Espinosa and Krebs 2014). According to Atlason and Unnthorsson (2014b), there are two methods for calculating the EPT. Both methods are explained here.

\subsubsection{Method 1, lifetime energy use}

The EPT using Method 1 is defined as the time required for a well to generate a certain amount of energy (converted into equivalent primary energy) to compensate for the energy consumption over its life cycle, including energy requirements in construction, operation, and maintenance (Peng et al. 2013). This method indicates when the plant will be producing net energy with all of the energy expenditures included. In this method, the cumulative energy output is equal to the total energy used for maintenance, operation, and construction over a 15-year lifetime. The input in the equation can be expressed as follows (Atlason and Unnthorsson 2014b):

$x(t)=a+(b+c) \cdot t$

where $x$ is the input energy over time $(t), a$ is the initial construction energy including the embodied energy within the construction materials, $b$ is the energy consumed in operation over a period of time $t$, and $c$ accounts for the maintenance for a given time period. The output is described by the following function:

$y(t)=d \cdot t$

where $d$ is the output from the plant. The EPT is reached using Method 1 when:

$y(t)=x(T)$

where $T$ is the expected lifetime of the plant, and $y$ is the energy output for a given time period.

\subsubsection{Method 2, real-time energy use}

The EPT using Method 2 shows that a given plant reaches an EROI of 1 when the energy expenditures are in chronological order. The difference between this method and the previous method is that the total energy used for operation and maintenance is not summed and included with plant construction but is considered to be ongoing throughout the lifetime of the plant (Atlason and Unnthorsson 2014b). The EPT using real-time energy use can be expected to differ slightly from the EPT using lifetime energy use. Using Method 2, the EPT is reached when:

$y(t)=x(t)$

\subsection{Greenhouse gas (GHG) emissions, global warming potential (GWP), and environmental inputs (ENI)}

The greenhouse gas (GHG) emissions from CSG systems have negative effects on biogeochemical cycles. For example, the increase of $\mathrm{N}_{2} \mathrm{O}$ not only reduces atmosphere transparency by absorbing infrared light and reducing earth surface radiation but also aggravates the destruction of the ozone layer ( $\mathrm{Xu}$ et al. 2016). Therefore, it is necessary to estimate the greenhouse gas emissions and their global warming potential. As illustrated in Fig. 1, the methodology for calculating the GWP comprises two steps:

- Air emissions assessment: This step involves taking an inventory of the GHG emissions during the life cycle of the energy supply (Kong et al. 2016a). The emissions to the atmosphere are assessed for each process. The amount of GHG emissions in CSG production is calculated using the carbon dioxide $\left(\mathrm{CO}_{2}\right)$, methane $\left(\mathrm{CH}_{4}\right)$, and nitrous oxide $\left(\mathrm{N}_{2} \mathrm{O}\right)$ emission coefficients of each process.

- GWP evaluation: The factors that represent the relative contributions of various gases to the greenhouse effect can be used to quantify the GWP (Bong et al. 2017). The GWP factor of a gas is defined as the sum of the radiative forcing potentials from the present to a selected time in the future caused by a unit mass of the gas emitted at the present (Yousefi et al. 2014). $\mathrm{CO}_{2}$ is regarded as a reference gas to evaluate the GWP factors (IPCC 2007).

The GWP was calculated as follows:

$\mathrm{GWP}=\sum_{i} \mathrm{GWP}_{i}=\sum_{i} \sum_{j} A_{i} \times \mathrm{EF}_{i j} \times \mathrm{GWP}_{j}$

where $A_{i}$ is the activity data at $i, i$ is the life-cycle stage, $\mathrm{EF}_{i j}$ is the emissions factor of emission $j$, and $\mathrm{GWP}_{j}$ is the 


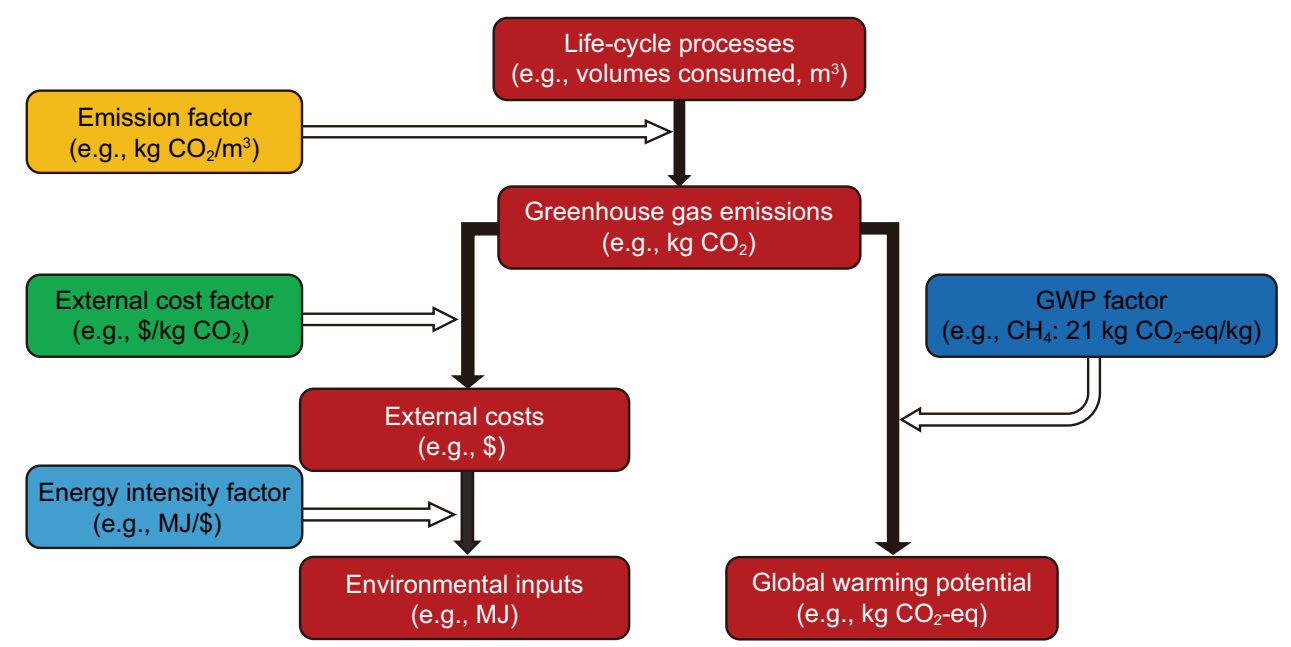

Fig. 1 Illustration of the ENI and GWP calculation approach

global warming potential factor of emission $j$. The score is expressed in terms of $\mathrm{CO}_{2}$ equivalents $\left(\mathrm{CO}_{2}\right.$-eq).

Energy systems have external costs as well, such as environmental costs, although they are usually more difficult to quantify in energy terms (Cleveland and O'Connor 2011). Reducing GHG emissions is recognized as a global task due to their global warming potential (Li et al. 2015). Additional energy is required to mitigate the GHG emissions from CSG production. As illustrated in Fig. 1, the methodology for the ENI calculation includes three steps:

- Air emissions assessment: This step was introduced above.

- Monetization: The monetization of damages from air emissions pollution is dependent on an external cost factor, which is the marginal damage cost based on the willingness of consumers to pay to prevent the damage (European Commission 2003).

- ENI evaluation: External costs are expressed in monetary or currency units (Kong et al. 2016a), which usually require conversion coefficients (in $\mathrm{MJ} /$ monetary unit) to convert them into energy units (Hu et al. 2013). The energy intensity by gross domestic product (GDP) is a specific and appropriate proxy for the conversion coefficient from money into joules (Hu et al. 2013).

Generally, the total ENI for the CSG life cycle can be calculated as follows:

$\mathrm{ENI}=\sum_{i} \mathrm{ENI}_{i}=\sum_{i} \sum_{j} A_{i} \times \mathrm{EF}_{i j} \times \mathrm{ECF}_{i j} \times \mathrm{EI}_{\mathrm{GDP}}$

where $\mathrm{ENI}_{i}$ represents the environmental inputs at lifecycle stage $i$ (in $\mathrm{MJ}$ ), $\mathrm{ECF}_{i j}$ refers to the external cost factor of emission $j$ (e.g. yuan $/ \mathrm{kg} \mathrm{CH}$ ), and $\mathrm{EI}_{\mathrm{GDP}}$ expresses the energy intensity by GDP (in MJ/yuan).

\section{Energy output and inputs}

This section estimates the energy outputs of CSG production, the energy inputs of CSG's life-cycle stages, and CSG losses during transportation.

\subsection{System boundary}

Selecting the appropriate boundaries is perhaps the most important step in an EROI analysis, but it is usually overlooked (Kong et al. 2015a). Different boundaries of the analysis can lead to significantly different results, even when they are applied to the same energy resource. Figure 2 shows the system boundary of the CSG used here. The EROI ${ }_{\text {stnd }}$ and EROI ${ }_{\text {ide }}$ are under system boundary 1, and the only difference is that for the former, the output is energy output 1, while for the later it is equal to energy output 1 plus the CSG losses during extraction. The $\mathrm{EROI}_{3, \mathrm{i}}$ and $\mathrm{EROI}_{3, \mathrm{i}+\mathrm{e}}$ are under system boundary 2 in which the output is energy output 2, which is equal to energy output 1 minus the CSG losses in transportation. The difference between them is that for $\mathrm{EROI}_{3, \mathrm{i}+\mathrm{e}}$, ENI should be considered, while for $\mathrm{EROI}_{3, \mathrm{i}} \mathrm{ENI}$ is not considered.

\subsection{Energy output}

Currently, many CSG wells, particularly those in China, have not been producing for a sufficient amount of time to determine their life-cycle gas production. However, based on existing production data and geological information, some researchers have provided a forecast method for CSG production. According to Yang et al. (2008) and Yang (2008), the Arps equation with hyperbolic decline can be used to forecast the gas production of a single well in the 


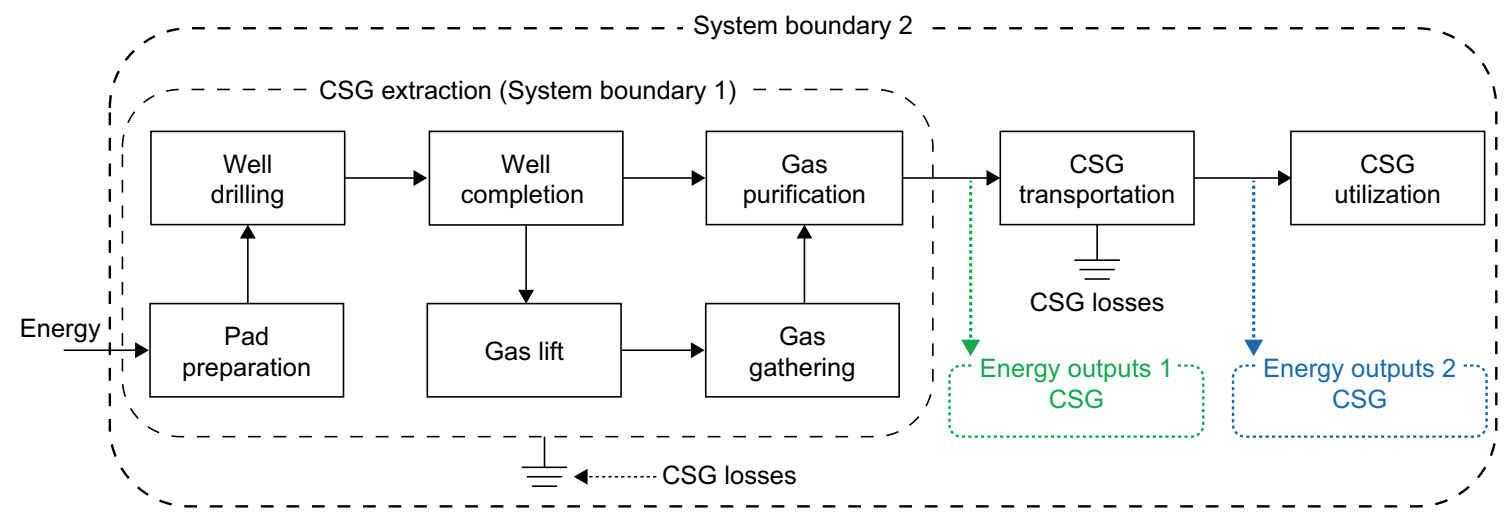

Fig. 2 The CSG system boundary

Fanzhuang block. The equation is given by Kong et al. (2016a):

$q=\frac{q_{i}}{\left(1+D_{i} b t\right)^{\frac{1}{b}}}$

where $D_{i}$ is the initial rate of decline, $b$ is the decline exponent $(0<b<1), q_{i}$ is the initial gas flow rate (in $\mathrm{m}^{3} /$ d), and $q$ is the gas flow rate at time $t$ (in $\mathrm{m}^{3} / \mathrm{d}$ ).

According to Li and Sun (2008) and Zhou and Zhang (2011), a well in the Fanzhuang block usually has a 15-20year lifespan. Here, we assume it has a 15-year lifespan. Based on Chen et al. (2009) and Yang (2008), we set $q_{i}=2500$ and $b=0.1$, respectively. The value of $D_{i}$ $(10 \%)$ is obtained by personal interview. The production forecast results shown in Fig. 3 have similar trend with the results from Zhou and Zhang (2011), who modelled and forecast the daily production of a vertical well in the Fanzhuang block. The predicted average daily production is $1549 \mathrm{~m}^{3} / \mathrm{d}$, which is very close to the actual value. $\mathrm{Mu}$ et al. (2009) and Wang et al. (2014) showed that as of November 2014, the average daily production of approximately $80 \%$ of the more than 500 vertical wells in the Fanzhuang block is in the range of $1200-1700 \mathrm{~m}^{3} / \mathrm{d}$.

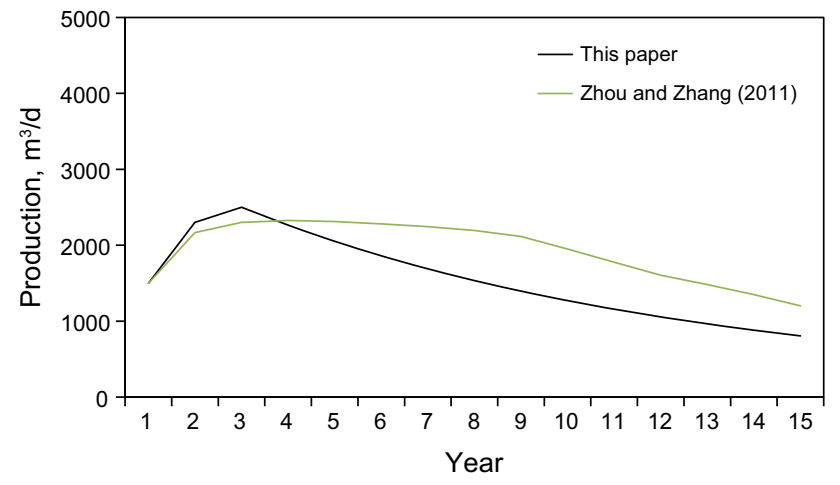

Table 2 Conversion factors from physical units to thermal units

\begin{tabular}{ll}
\hline Fuel & Average calorific value \\
\hline Natural gas & $34.6 \mathrm{MJ} / \mathrm{m}^{3}$ \\
Diesel & $42.7 \mathrm{MJ} / \mathrm{kg}$ \\
Engine oil & $36.0 \mathrm{MJ} / \mathrm{kg}$ \\
Electricity & $3.6 \mathrm{MJ} / \mathrm{kg}$ \\
\hline
\end{tabular}

To calculate the EROI ${ }_{\text {ide }}$, it is necessary to determine the theoretical maximum output. Here, it is estimated by the following equation:

$q_{\text {ide }}=\frac{q}{1-r}$

where $q_{\text {ide }}$ is the theoretical maximum output, $q$ is the energy output under the current mining conditions, and $r$ is the gas loss rate during the CSG extraction process (in \%). Bai et al. (2001), Li and Sun (2008), and Zhou and Zhang (2011) found $r$ values for the Fanzhuang block of $41 \%$, $50 \%$, and $46 \%$, respectively. The average value of their results is $45.7 \%$, which is used here. Figure 3 shows $q$. Therefore, $q_{\text {ide }}$ can be estimated by Eq. (14). When calculating the EROI, $q$ and $q_{\text {ide }}$ are directly converted to heat units using the values in Table 2.

\subsection{Energy inputs}

In Sects. 3.3.1 and 3.3.2, this paper estimates the direct and indirect energy investment in gas extraction and transportation, respectively. In Sect. 3.3.3, the ENI for the CSG life cycle is provided. In Sect. 3.3.4, CSG losses during transportation are estimated.

Fig. 3 Prediction of the life-cycle daily output of a CSG well 


\subsubsection{Energy investment in CSG extraction}

Energy investment in pad preparation Pad preparation for CSG wells mainly includes site clearing, road pavement, water system construction, power equipment installation, and some other ground engineering to create a foundation for the subsequent process. Pads in this area cover approximately $3600 \mathrm{~m}^{2}$ (Zhou and Zhang 2011). The unit energy consumption for pad preparation is $80.2 \mathrm{MJ} / \mathrm{m}^{2}$ (Sun 2015). Thus, energy investment in pad preparation is equal to 304,760 MJ (Table 3).

Energy investment in well drilling and completion As shown in Table 3, three types of energy inputs, including fuel inputs, raw material inputs, and other costs, are associated with well drilling and completion (Yang 2008). The fuel inputs (diesel and engine oil) are converted directly into joules using the fixed conversion factors (Table 2). The raw material inputs (drill bits, drilling fluid, casing, casing accessories, cement, and slurry) and other costs, which are classified as indirect inputs, are converted to joules through their amounts in monetary terms multiplied by the Chinese industrial energy intensity, which was approximately 3.3 MJ/yuan in 2015 (Xu et al. 2014).

Energy investment in CSG lifting, gathering, and purification According to Sun (2015), $0.04104 \mathrm{MJ}$ of electricity is consumed in lifting $1 \mathrm{~m}^{3}$ of natural gas (Table 3). Li (2015) and Sun (2015) found that 1.4284 and $1.1866 \mathrm{MJ}$ of natural gas, respectively, will be consumed to gather $1 \mathrm{~m}^{3}$ of natural gas. In this paper, we use the average value of the above two studies, i.e. $1.3075 \mathrm{MJ}$ of natural gas. The unit energy consumption for gas purification is $0.7182 \mathrm{MJ} / \mathrm{m}^{3}$ (Sun 2015; He et al. 2016), and the total direct material inputs for lifting, gathering, and purifying $1 \mathrm{~m}^{3}$ of natural gas are $0.0396 \mathrm{MJ}$ (Yang 2008). The embodied energies in the equipment for gas lifting,
Table 3 Primary energy inputs in CSG extraction

\begin{tabular}{|c|c|c|c|c|c|}
\hline No. & Input & Quantity & Unit & Input, MJ & Input type \\
\hline 1 & Pad preparation & & & 304,760 & \\
\hline 2 & Well drilling & & & & \\
\hline 2.1 & Diesel & 14 & $\mathrm{t}$ & 597,800 & $E_{\text {direct }}$ \\
\hline 2.2 & Engine oil & 0.7 & $\mathrm{t}$ & 25,200 & $E_{\text {direct }}$ \\
\hline 2.3 & Drill bit & 33,500 & yuan & 110,550 & $E_{\text {indirect }}$ \\
\hline 2.4 & Drilling fluid & 38,850 & yuan & 128,205 & $E_{\text {indirect }}$ \\
\hline 2.5 & Casing & 151,500 & yuan & 499,950 & $E_{\text {indirect }}$ \\
\hline 2.6 & Casing accessories & 24,385 & yuan & 80,471 & $E_{\text {indirect }}$ \\
\hline 2.7 & Cement & 31,700 & yuan & 104,610 & $E_{\text {indirect }}$ \\
\hline 2.8 & Slurry & 38,900 & yuan & 128,370 & $E_{\text {indirect }}$ \\
\hline 2.9 & Others & 199,900 & yuan & 659,670 & $E_{\text {indirect }}$ \\
\hline 3 & Well completion & & & & \\
\hline 3.1 & Diesel & 1.22 & $\mathrm{t}$ & 52,214 & $E_{\text {direct }}$ \\
\hline 3.2 & Water & 2960 & yuan & 9768 & $E_{\text {indirect }}$ \\
\hline 3.3 & Chemicals & & & 44,222 & $E_{\text {indirect }}$ \\
\hline 3.4 & Equipment & & & 293,000 & $E_{\text {indirect }}$ \\
\hline 4 & Gas lift & & & & \\
\hline 4.1 & Electricity & 0.0114 & $\mathrm{kWh} / \mathrm{m}^{3}$ & & $E_{\text {direct }}$ \\
\hline 4.2 & Equipment & 587,000 & yuan & $1,937,100$ & $E_{\text {indirect }}$ \\
\hline 5 & Gas gathering & & & & \\
\hline 5.1 & Natural gas & 1.3075 & $\mathrm{MJ} / \mathrm{m}^{3}$ & & $E_{\text {direct }}$ \\
\hline 5.2 & Gas gathering station & 287,437 & yuan & 948,542 & $E_{\text {indirect }}$ \\
\hline 5.3 & Gas gathering pipelines & 0.67 & $\mathrm{~km}$ & 1337 & $E_{\text {indirect }}$ \\
\hline 6 & Gas purification & & & & \\
\hline 6.1 & Natural gas & 0.7182 & $\mathrm{MJ} / \mathrm{m}^{3}$ & & $E_{\text {direct }}$ \\
\hline 6.2 & Equipment & & & 960,000 & $E_{\text {indirect }}$ \\
\hline 7 & Direct material inputs* & 0.0396 & $\mathrm{MJ} / \mathrm{m}^{3}$ & & $E_{\text {direct }}$ \\
\hline 8 & Maintenance $^{* *}$ & & & $1,730,539$ & \\
\hline
\end{tabular}

*Direct material inputs in gas lifting, gathering, and purification

**The total energy investment in maintenance in CSG extraction 
gathering, and purification are 1937,100, 949,879, and 960,000 MJ, respectively (Yang 2008).

Energy investment in maintenance According to Sun (2015), the maintenance on the plant in the Fanzhuang block will account for $3 \%$ of the original engine and electrical appliance embodied energy annually, which amounts to $115,369 \mathrm{MJ}$ per year or 1,730,539 MJ for the first 15 years of the plant's life. Because no other data were available, this parameter was used.

Table 3 lists the primary energy inputs in CSG extraction, which are classified as direct energy inputs $\left(E_{\text {direct }}\right)$ or indirect energy inputs $\left(E_{\text {indirect }}\right)$. In Table 3 , using line numbers, $\quad a=1+2+3+4.2+5.2+5.3+6.2$, $b=4.1+5.1+6.1+7$, and $c=8$.

\subsubsection{Energy investment in CSG transportation}

The CSG produced in Fanzhuang is expected to pass through the Qinshui CSG pipeline and the West-East Gas Pipeline to Shanghai (Xue et al. 2011). The Qinshui coalbed methane pipeline, which is $43 \mathrm{~km}$ long, is China's first coalbed gas pipeline (Xue et al. 2011). The West-East Gas Pipeline, which runs from Qinshui to Shanghai, is approximately $1064 \mathrm{~km}$ long (Ren 2015a). Therefore, the total transportation distance is approximately $1107 \mathrm{~km}$. The traffic intensity by gas pipeline is approximately $0.372 \mathrm{MJ} / \mathrm{ton}-\mathrm{km}$ (Ou et al. 2011). Therefore, the energy inputs in CSG transportation can be estimated by multiplying the transport volume, the traffic intensity, and the transport distance.

\subsubsection{ENI for the CSG life cycle}

Here, the GHG emissions boundary for CSG includes three stages: CSG extraction, transportation, and utilization. The main emissions that were considered include $\mathrm{CO}_{2}, \mathrm{CH}_{4}$, and $\mathrm{N}_{2} \mathrm{O}$. The $\mathrm{EF}_{j}$ values of the GHG profile for each lifecycle stage of CSG are present in Table 4, which are collected from the existing academic literature, including Skone and Littlefield (2013) and Su et al. (2015). The $\mathrm{ECF}_{j}$ values in Table 5 are taken from $\mathrm{Li}$ et al. (2014). According to Kong et al. (2016a), the Chinese energy

Table 4 Emission factors of air emissions

\begin{tabular}{llll}
\hline & $\mathrm{CO}_{2}$ & $\mathrm{CH}_{4}$ & $\mathrm{~N}_{2} \mathrm{O}$ \\
\hline CSG extraction, $\mathrm{kg} / \mathrm{m}^{3}$ & $7.68 \mathrm{E}-02$ & $4.48 \mathrm{E}-03$ & $2.74 \mathrm{E}-06$ \\
CSG transportation, $\mathrm{kg} / \mathrm{m}^{3}-\mathrm{km}$ & $1.60 \mathrm{E}-05$ & $3.87 \mathrm{E}-06$ & $1.73 \mathrm{E}-09$ \\
CSG utilization, $\mathrm{kg} / \mathrm{m}^{3}$ & $1.93 \mathrm{E}+00$ & $3.08 \mathrm{E}-03$ & $1.00 \mathrm{E}-04$ \\
\hline
\end{tabular}

Table 5 External cost factors of air emissions

\begin{tabular}{llll}
\hline & $\mathrm{CO}_{2}$ & $\mathrm{CH}_{4}$ & $\mathrm{~N}_{2} \mathrm{O}$ \\
\hline$E C F_{j}$, yuan $/ \mathrm{kg}$ & 0.198 & 1.488 & 32.426 \\
\hline
\end{tabular}

intensity by GDP was $1.898 \mathrm{MJ} / \mathrm{yuan}$ in 2015 , which was adjusted based on constant 2010 prices.

The ENI values of each life-cycle stage are calculated using Eq. (12) and are present in Fig. 4. The CSG utilization stage accounts for $92.4 \%$ of the total ENI, followed by the CSG extraction stage (5.2\%) and the CSG transportation stage $(2.4 \%)$. In the CSG extraction and utilization stages, most of the ENI is used to reduce the environmental impact of $\mathrm{CO}_{2}$ emissions, while in the CSG transportation stage, more ENI could be used to control the $\mathrm{CH}_{4}$ emissions. In general, the control of $\mathrm{CO}_{2}$ emissions is responsible for most of the ENI; it accounts for $95 \%$ of the CSG life cycle, followed by $\mathrm{CH}_{4}$ emissions. A very small proportion of the ENI is used to control the $\mathrm{N}_{2} \mathrm{O}$ emissions.

\subsection{CSG losses during transportation}

In China, domestic gas transportation mainly relies on gas pipelines and LNG/CNG (compressed natural gas) trucks (Zhang et al. 2016). During transportation by LNG/CNG trucks, as long as the pressure in the vessel does not exceed the design pressure, there is no product loss during transportation (Lin et al. 2010); however, gas losses during transportation by pipeline are usually caused by fugitive emissions, flaring, and own use (Zhang et al. 2014). The gas losses in pipeline transportation can be calculated by the following equation:

$L_{t}=M_{t} \times D_{t} \times L R$

where $L_{t}$ is the amount of gas losses, $\mathrm{kg} ; M_{t}$ is the amount of gas transported, $\mathrm{m}^{3} ; L R$ is the loss rate caused by

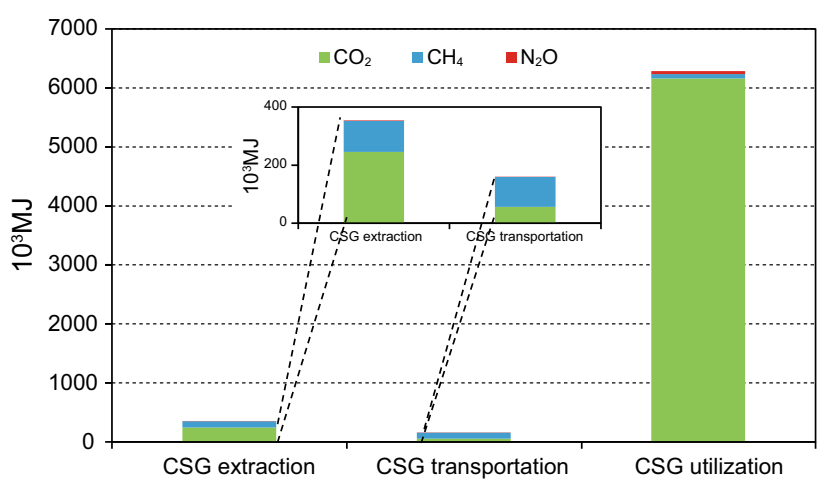

Fig. 4 ENI of the CSG life cycle 
fugitive emissions, flaring, and own use during transportation, $\mathrm{kg} / \mathrm{m}^{3}$.

The CSG that is produced in the Fanzhuang block is transported approximately $1064 \mathrm{~km}$ by pipeline to Shanghai. In this paper, the volume of gas transported is equal to the production of CSG shown in Fig. 3. The CSG transport is mainly dependent on the West-East Gas Pipeline. According to Zhang et al. (2014), Ren (2015b), and Kong et al. (2016a), the $L R$ for the West-East Gas Pipeline is $1.23 \times 10^{-6} \mathrm{~kg} / \mathrm{m}^{3}-\mathrm{km}$. According to Eq. (15), the value of $L_{t}$ for CSG transportation can be easily calculated.

\section{Results}

The $\mathrm{EROI}_{\text {stnd }}, \mathrm{EROI}_{\mathrm{ide}}, \mathrm{EROI}_{3, \mathrm{i}}, \mathrm{EROI}_{3, \mathrm{i}+\mathrm{e}}$, and EPT for the gas production of a single well were calculated using different lifetime scenarios. In addition, the GHG and GWP for the CSG life cycle were estimated.

\section{1 $\mathrm{EROI}_{\text {stnd }} \mathrm{EROI}_{\text {ide, }} \mathrm{EROI}_{3, \mathrm{i}}$ and $\mathrm{EROI}_{3, \mathrm{i}+\mathrm{e}}$}

The EROI is calculated for a single well in the Fanzhuang CSG field using the two methods. The results using Method A are shown in Fig. 5, which indicates that the EROI ${ }_{\text {stnd }}$ is 11:1 over the first 15 years of the lifetime of the single CSG well. It increases rapidly in the beginning but levels off as operational and maintenance costs increase. Figure 5 illustrates that the $\mathrm{EROI}_{\text {ide }}$ increases almost linearly over the lifetime and is 20:1 after 15 years. This EROI represents the potential for improvement. Compared to the $\mathrm{EROI}_{\text {stnd }}$, the $\mathrm{EROI}_{3, \mathrm{i}}$ decreases by $36.4 \%$ over the first 15 years of the operational life and reaches $7: 1$. When the environmental input is considered, the $\mathrm{EROI}_{3, \mathrm{i}}$ decreases by $14.8 \%$. The $\mathrm{EROI}_{3, \mathrm{i}+\mathrm{e}}$ is approximately $6: 1$.

Using Method B, as expected, the EROI values have the same general pattern within different boundaries: an increase to a maximum in 1-3 years of operation and then a sharp decline throughout the remaining time (Fig. 5). Specifically, the EROI ${ }_{\text {stnd }}$ increases from 10.8:1 in the first year to $12.5: 1$ in the third year and then declines to $8.4: 1$. The EROI ${ }_{\text {ide }}$ values are approximately $90 \%$ higher than the EROI $_{\text {stnd }}$. The EROI ${ }_{\text {ide }}$ first increases from 20:1 to 23.1:1 and then declines to $15.6: 1$ as production continues. Compared to the $\mathrm{EROI}_{\text {stnd }}$, the $\mathrm{EROI}_{3, \mathrm{i}}$ decreases by $30.6 \%-39.5 \%$. The $\mathrm{EROI}_{3, \mathrm{i}}$ rises from 9.9:1 in the first year to $11.3: 1$ in the third year and then drops to $8.4: 1$. In the first year, the $\mathrm{EROI}_{3, \mathrm{i}+\mathrm{e}}$ is $8: 1$, and after two years, it increases to $8.9: 1$. It declines to $6.6: 1$ in the last year.

\subsection{Energy payback time}

The EPT is calculated for a single well in the Fanzhuang CSG field using the two methods. Figure 6 depicts different energy payback times using Method 1, where all of the energy expenditures over the lifetime are included. This result shows that the EROI ${ }_{\text {ide }}$ has the shortest payback time of approximately 9 months. The $\mathrm{EROI}_{3, \mathrm{i}+\mathrm{e}}$ is found to have the longest payback time of approximately 24-25 months

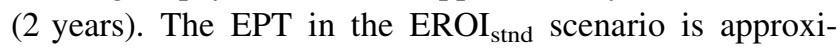
mately 15 months (1.25 years), which is a half year more than that of $\mathrm{EROI}_{\text {ide }}$ and $\mathrm{EROI}_{3, \mathrm{i}}$, which is approximately 20-22 months.

Method 2 is also used to calculate the EPT, where consumption is analysed using a real-time sequence instead of counting the total energy consumption over its lifetime. Similar to the results using Method 1, the EPT in the EROI $_{\text {ide }}$ scenario is the shortest at slightly less than 11 weeks. The results show that the EPT in the EROI ${ }_{\text {stnd }}$ scenario is approximately 21-22 weeks, which is approximately twice that of the EROI ${ }_{\text {ide }}$ scenario. The $\mathrm{EROI}_{3, \mathrm{i}}$ and $\mathrm{EROI}_{3, \mathrm{i}+\mathrm{e}}$ are found to have almost the same EPT of approximately 22 weeks (5.5 months). The results from Method 2 are also shown in Fig. 6. (a)

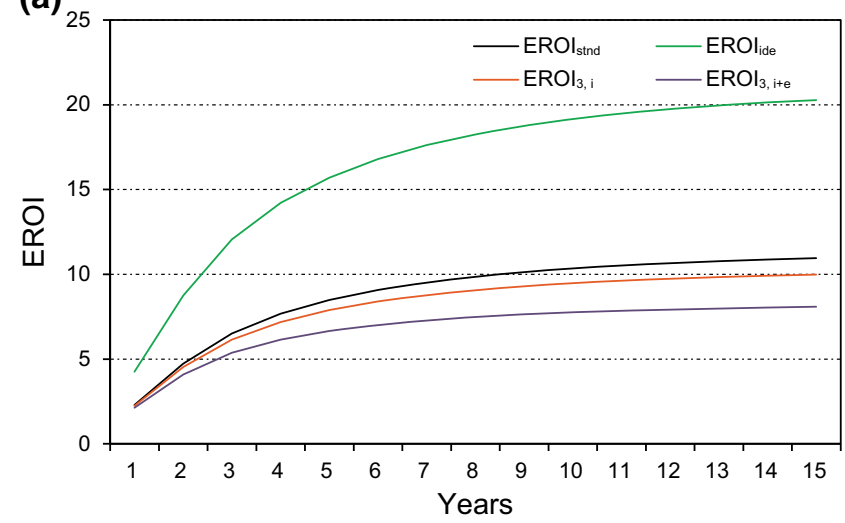

(b)

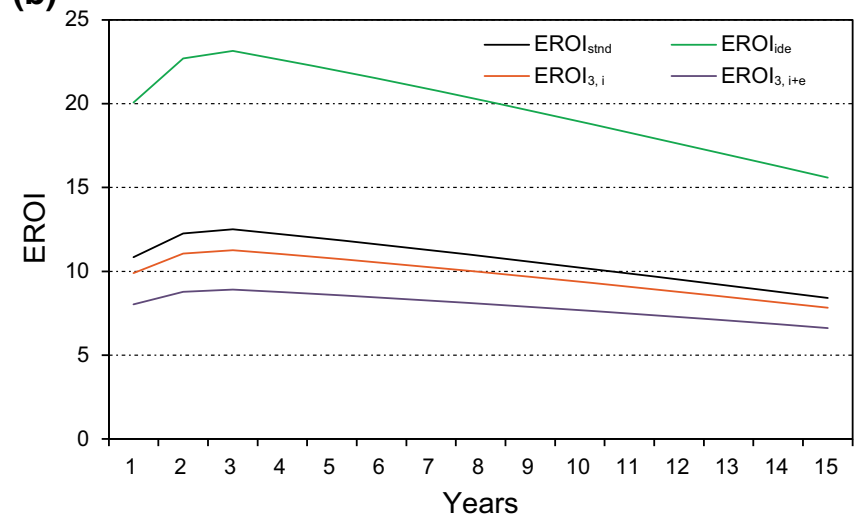

Fig. 5 EROI values within different boundaries calculated using Method A (left) and Method B (right) 
(a)

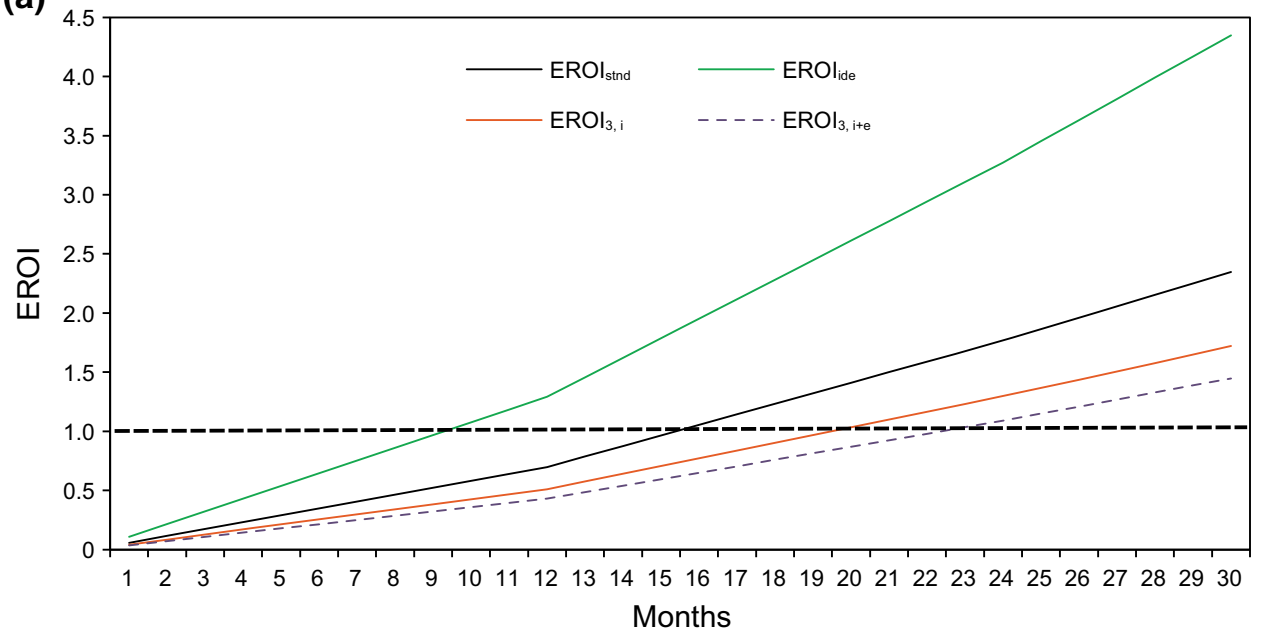

(b)

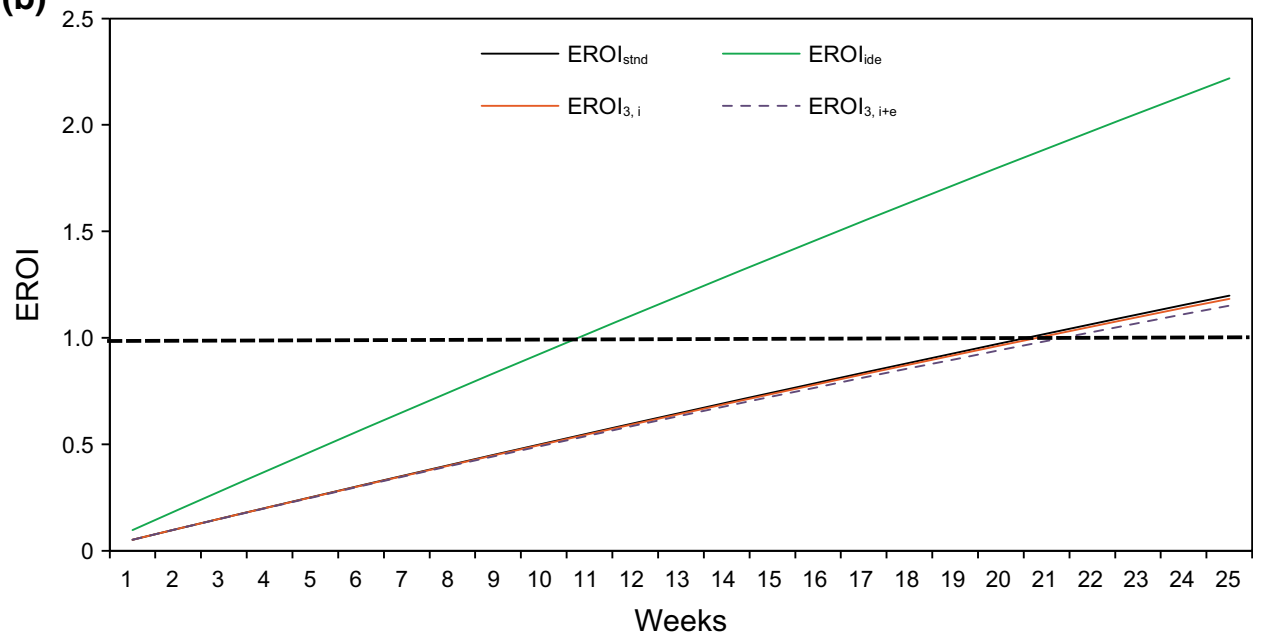

Fig. 6 Energy payback times of the different EROI scenarios calculated using Method 1 (left) and Method 2 (right)

It can be seen that the EPT using Method 1 is shorter than that using Method 2. The reason is that the EPT using Method 1 is defined as the time required for a well to generate a certain amount of energy to compensate for the energy consumption over its life cycle, including energy requirements in construction, operation, and maintenance; however, using Method 2, the total energy used for operation and maintenance is not summed and included with plant construction but is considered to be ongoing throughout the lifetime of the plant, which means that the energy outputs used to compensate for the energy consumption using Method 1 are more than that using Method 2.

\subsection{Greenhouse gas emissions and global warming potential}

The $\mathrm{EF}_{j}$ values for the GHG profile of each life-cycle stage of CSG are present in Table 4. According to the IPCC
(2007), the GWP factors for $\mathrm{CO}_{2}$ (on a 100-year time horizon), $\mathrm{CH}_{4}$, and $\mathrm{N}_{2} \mathrm{O}$ are 1,25 , and 298, respectively (U.S Department of Energy 2014). Thus, we can calculate the GWP of the CSG life cycle. The results show that $\mathrm{CO}_{2}$, $\mathrm{CH}_{4}$, and $\mathrm{N}_{2} \mathrm{O}$ emissions from the CSG systems are $17,156,091,100,394$, and $889 \mathrm{~kg}$, respectively. In terms of $\mathrm{CO}_{2}$ equivalents, the total GWPs are $19.9 \times 10^{6} \mathrm{~kg} \mathrm{CO}_{2}-$ eq in the CSG systems. The highest share of the GWPs is related to $\mathrm{CO}_{2}(86.1 \%)$ then $\mathrm{CH}_{4}(12.6 \%)$ and finally $\mathrm{N}_{2} \mathrm{O}$ $(1.3 \%)$. The values of GWP for different emissions in each life-cycle stage are calculated using Eq. (11), as given in Fig. 7. Figure 7 shows that based on the greenhouse effect, the highest share is related to the CSG utilization stage $\left(17,259,814 \mathrm{~kg} \mathrm{CO}_{2}\right.$-eq), which accounts for $86.6 \%$ of the total GWP. The GWP related to CSG extraction and CSG transportation is $1,608,325$ and $1,062,874 \mathrm{~kg} \mathrm{CO}_{2}$-eq, respectively. In the CSG utilization stage, $\mathrm{CO}_{2}$ is the biggest contributor to the greenhouse effect, while for CSG 


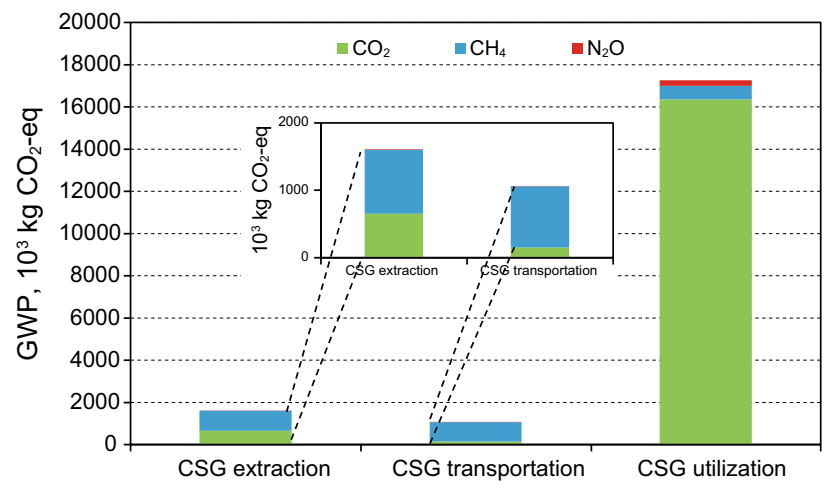

Fig. 7 GWP for the CSG life cycle

extraction and transportation, $\mathrm{CH}_{4}$ is the biggest contributor.

\section{Discussion}

Sun (2015) showed that the EROI of CSG production is approximately 9.5 , which is very close to our results. The reasons that the EROI of Sun's study is slightly lower than our results are that in his study, except for the direct and indirect energy inputs, the labour costs were incorporated into the total energy inputs, and the EROI $\mathrm{Etnd}_{\text {sas not }}$ calculated. China's natural gas strategy for the future is crucial to the country's overall economic development and well-being (Hu et al. 2013). Faced with a gas shortage, it has been necessary for societies to find sound alternative energy resources. EROI analysis is useful for determining whether developing a new source of energy is feasible from a net energy perspective (Kittner et al. 2016). Figure 8 shows a comparison of the EROIs of several gas sources in China, including CSG, conventional oil and gas, imported gas, shale gas, tight gas, and coal-based synthetic natural gas (SNG) in China.

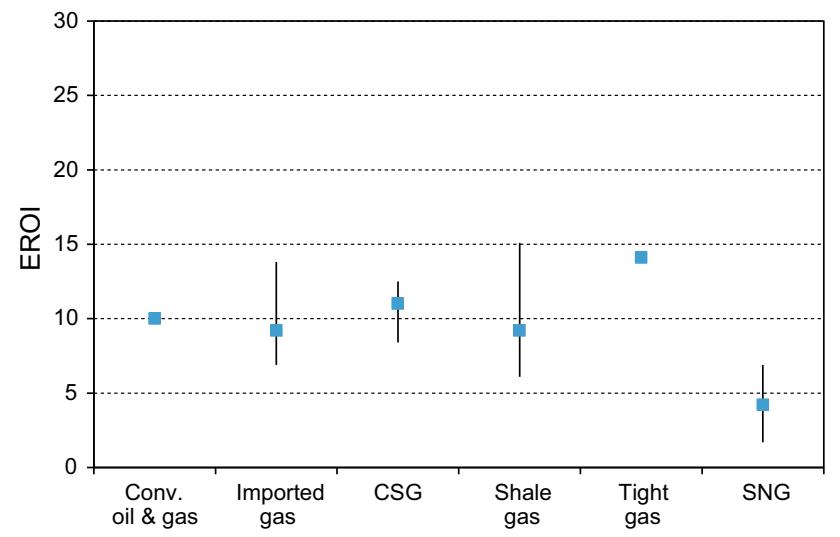

Fig. 8 Mean EROI values of China's various gas sources from published values
Because the energy inputs for oil and gas extraction are combined in China, the EROI of conventional gas cannot be calculated. The EROI for conventional oil and gas is approximately 10:1 (Hu et al. 2013), which is slightly lower than that of CSG. However, the EROI of conventional gas is expected to be higher than that of CSG because gas production is in the initial development stage, which implies a higher EROI than for oil production (Kong et al. 2016b). Currently, the slow development of conventional gas is due to access restrictions and government pricing, which should be abolished in the future.

Imported gas has a relatively favourable EROI in the range of 6.9:1-13.8:1 (Kong et al. 2015b), which is similar to CSG. In the current situation, in which the domestic gas supply cannot meet demand and gas import dependency is relatively low, imported gas is also a good choice from the net energy perspective. However, according to the BP Energy Outlook 2035 (BP 2015), China's dependency on imported natural gas (ING) will continue to increase (Fig. 9) and will exceed $40 \%$ by 2030 , which is expected to threaten gas security. With high dependency on foreign gas, the economy would be seriously affected by a gas import interruption. For example, in December 2015, when extremely foggy weather resulted in the aborted installation of imported gas from an LNG carrier, a gas shortage in North China resulted in a severe impact to the local economy, particularly in the heating sectors (Xiahuanet 2015). Therefore, from the energy security perspective, China should take measures to promote domestic gas production, especially unconventional gas, which exists in rich resource reserves.

Because of the success of US shale gas, China currently focuses more on shale gas than other unconventional gas sources ( $\mathrm{Pi}$ et al. 2015). However, similar to shale gas, CSG and tight gas have relatively high EROIs, including 10:1 for CSG and 14:1 for tight gas. In addition, as shown in Sect. 5, the EPT of CSG within different boundaries is no more than 2 years. This study further showed that the EROI $_{\text {ide }}$ is 20:1, which means that the EROI of CSG can be improved significantly. In addition, over the next 10 years, shale gas cannot be used to close the increasing gap between demand and supply because of the lack of proven resources, the large investments required for exploration and development, and low gas prices (Lin and Wang 2012; Wang et al. 2013). Therefore, the Chinese government should provide more support to the development of CSG. Figure 8 shows that the EROI of SNG is lower than that of $\mathrm{CSG}$, even at or near the break-even point $(\mathrm{EROI}=1)$, which means that SNG is not a good choice. However, the Chinese government has aggressively supported SNG in the form of supportive policies as well as financial support from policy banks. Approximately 54 SNG projects are currently in the planning stage with a total capacity of 


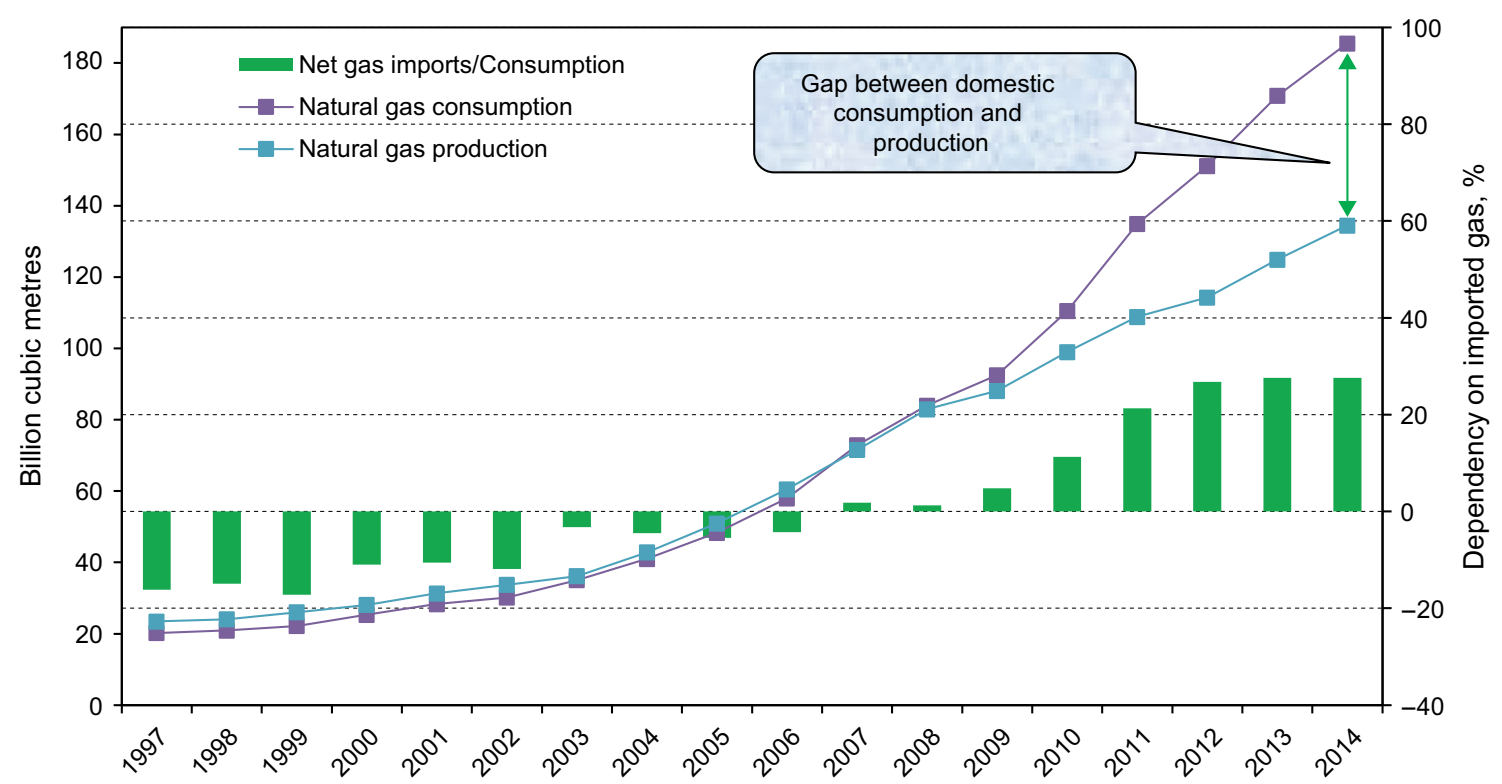

Fig. 9 Natural gas production and consumption in China

$163.8 \mathrm{bcm} / \mathrm{y}$, which is similar to China's gas consumption in 2013 (Zhang et al. 2016). In the short term, it is inappropriate to develop SNG on a large scale in China. Of course, the government may regard coal gasification technology as a strategic technology reserve and continue providing support to related research.

In gas-scarce countries, the development of the CSG industry could be hindered by environmental concerns, particularly regarding GHG emissions. Several technologies, such as carbon capture and storage (CCS), are available to reduce GHG emissions, although their utilization would increase the energy inputs and decrease the EROI. This study indicates that when additional inputs to control GHG emissions, including $\mathrm{CO}_{2}, \mathrm{CH}_{4}$, and $\mathrm{N}_{2} \mathrm{O}$, are considered, the EROI decreases by $19.2 \%-46.8 \%$. In addition, the added cost of environmental technology will make it more difficult for CSG to compete with other fuels. With the deterioration of the environment, environmental technology could become compulsory for energy producers. China should gradually improve its laws and regulations for environmental protection with reference to the legislation that is already in place in advanced countries (Zeng et al. 2014). Furthermore, China must investigate additional methods to develop environmental technologies that consume less energy. To control $\mathrm{CO}_{2}$ emissions, which are the largest emissions in the CSG life cycle, CCS is available and can be applied to the CSG production process. Specifically, captured $\mathrm{CO}_{2}$ can be injected into a coal seam to replace the CSG to allow more CSG to be produced from the coal (Bergen et al. 2011). This technology is often referred to as $\mathrm{CO}_{2}$-enhanced coalbed methane $\left(\mathrm{CO}_{2}\right.$-ECBM) production (Wu et al. 2011; Bergen et al.
2011) and not only reduces $\mathrm{CO}_{2}$ emissions but also enhances recovery. To reduce $\mathrm{CH}_{4}$ emissions, which are the second largest emissions, Chinese CSG companies may take part in the Natural Gas STAR International Program, which was launched by the USEPA in 2006 to increase the opportunities to reduce methane emissions from oil and natural gas operations worldwide and create a framework for the global application of the program's principles, including cost-effective $\mathrm{CH}_{4}$ emissions reduction technology and practical implementation (USEPA 2016).

\section{Conclusions}

In this paper, we systematically analysed the EROI, EPT, and GWP of a single CSG well in the Qinshui Basin to provide a reference for policy makers and investors.

The results show that using Method A, over a 15-year lifetime, $\mathrm{EROI}_{\text {stnd }}, \mathrm{EROI}_{\mathrm{ide}}, \mathrm{EROI}_{3,1}$, and $\mathrm{EROI}_{3,1+\mathrm{e}}$ are expected to deliver EROIs of approximately 11:1, 20:1, 7:1, and 6:1, respectively. Using Method B, the EROI ${ }_{\text {stnd }}$, $\mathrm{EROI}_{\text {ide }}, \mathrm{EROI}_{3, \mathrm{i}}$, and $\mathrm{EROI}_{3, \mathrm{i}+\mathrm{e}}$ increase from 10.8:1, 20.1:1, 9.9:1, and 8:1 in the first year to $12.5: 1,23.1: 1$, 11.3:1, and $8.9: 1$ in the third year, respectively, and then decline to $8.4: 1,15.6: 1,7.8: 1$, and 6.6:1, respectively. The EPT within different boundaries is no more than 2 years, and the life-cycle GHG emissions are approximately 18.8 million $\mathrm{kg} \mathrm{CO}_{2}$-eq. The results show that CSG has a fairly favourable energy return and a relatively short energy payback time, which indicates that policy makers should encourage the development of the CSG industry. In addition, several suggestions were provided for policy makers: 
(1) Rationalizing the domestic gas pricing mechanism. In the short run, it is necessary and feasible to perfect the existing netback pricing mechanism. Detailed measures should include: gradually reducing residential and non-residential cross-subsidization; perfecting the dynamic adjustment pricing mechanism; and introducing differential pricing policies such as seasonal price disparities. In the long run, the government should fully open gas pricing to realize market-oriented pricing.

(2) Promoting technological efficiency. Relying on national science and technology major projects on CSG development, research the key technologies and core equipment to further improve the recovery rate; optimize the operation mode of large-calibre long-distance pipeline gas turbines to reduce pipeline energy consumption.

(3) Developing environmental technologies. The government provides CSG companies tax incentives and financial subsidies to support their environmental technology research and development. Furthermore, China must strengthen international cooperation and introduce foreign advanced environmental technology. For example, to reduce $\mathrm{CH}_{4}$ emissions, Chinese CSG companies may take part in the Natural Gas STAR International Program.

Acknowledgements This work was supported by the National Natural Science Foundation of China (No. 71273277, 71722003, 71690244), the Philosophy and Social Sciences Major Research Project of the Ministry of Education (No. 11JZD048), and the National Key R\&D Program (2016YFC0208901).

Open Access This article is distributed under the terms of the Creative Commons Attribution 4.0 International License (http://crea tivecommons.org/licenses/by/4.0/), which permits unrestricted use, distribution, and reproduction in any medium, provided you give appropriate credit to the original author(s) and the source, provide a link to the Creative Commons license, and indicate if changes were made.

\section{References}

Atlason RS, Unnthorsson R. Hot water production improves the energy return on investment of geothermal power plants. Energy. 2013;51:273-80. https://doi.org/10.1016/j.energy.2013.01.003.

Atlason RS, Unnthorsson R. Ideal EROI (energy return on investment) deepens the understanding of energy systems. Energy. 2014a;67:241-5. https://doi.org/10.1016/j.energy.2014.01.096.

Atlason RS, Unnthorsson R. Energy return on investment of hydroelectric power generation calculated using a standardised methodology. Renew Energy. 2014b;66:364-70. https://doi.org/ 10.1016/j.renene.2013.12.029.

Aucott ML, Melillo JM. A preliminary energy return on investment analysis of natural gas from the Marcellus Shale. J Ind Ecol. 2013;17:668-79. https://doi.org/10.1111/jiec.12040.
Bai WH, Zhao QB, Liu RE. Predicting the recovery efficiency of the Qinshui coalbed methane field, Shanxi Province. Geoscience. 2001;15:438-44 (in Chinese).

Bai ZR, Zhang K. Analysis of China's CBM conditions. China Pet Explor. 2015;20:74-80. https://doi.org/10.3969/j.issn.16727703.2015.05.008 (in Chinese).

Bergen F, Tambach T, Pagnier $\mathrm{H}$. The role of $\mathrm{CO}_{2}$-enhanced coalbed methane production in the global CCS strategy. Energy Procedia. 2011;4:3112-6. https://doi.org/10.1016/j.egypro.2011.02. 224.

Bong CPC, Lim LY, Ho WS, Lim JS, Klemeš JJ, Towprayoon S, et al. A review on the global warming potential of cleaner composting and mitigation strategies. J Clean Prod. 2017;146:149-57. https://doi.org/10.1016/j.jclepro.2016.07.066.

BP. BP energy outlook 2035. http://www.bp.com/content/dam/bp/ pdf/energy-economics/energy-outlook-2016/bp-energy-outlook2015.pdf (2015). Accessed 10 Jan 2016.

Clark T, Hynes R, Mariotti P. Greenhouse gas emissions study of Australian CSG to LNG. http://www.abc.net.au/radionational/ linkableblob/4421188/data/greenhouse-gas-emissions-study-ofaustralian-csg-to-lng-data.pdf. (2011). Accessed 31 Mar 2016.

Cleveland CJ, O'Connor PA. Energy return on investment (EROI) of oil shale. Sustainability. 2011;3:2307-22. https://doi.org/10. 3390/su3112307.

Chen ZH, Wang YB, Yang JS, Wang XH, Chen YP, Zhao QB. Influencing factors on coal-bed methane production of a single well: a case of the Fanzhuang Block in the south part of Qinshui Basin. Acta Petrolei Sinica. 2009;30(3):410-2 (in Chinese).

Dale AT, Khanna V, Vidic RD, Bilec MM. Process based life-cycle assessment of natural gas from the Marcellus Shale. Environ Sci Technol. 2013;47:5459-66. https://doi.org/10.1021/es304414q.

Espinosa N, Krebs FC. Life cycle analysis of organic tandem solar cells: When are they warranted? Sol Energy Mater Sol Cells. 2014;120:692-700. https://doi.org/10.1016/j.solmat.2013.09. 013.

European Commission. Study on external environmental effectsfinal report. http://ec.europa.eu/environment/ipp/pdf/ext_effects finalreport.pdf (2003). Accessed 31 Mar 2016.

Hall CAS, Lambert JG, Balogh SB. EROI of different fuels and the implications for society. Energy Policy. 2014;64:141-52. https:// doi.org/10.1016/j.enpol.2013.05.049.

He HL, Zhou XT, Wang PF. Study on CBM dehydration and energy conservation technology. Chem Eng Manag. 2016;7:178-9 (in Chinese).

Hu Y, Feng LY, Hall CCS, Tian D. Analysis of the energy return on investment (EROI) of the huge Daqing oil field in China. Sustainability. 2011;3:2323-38. https://doi.org/10.3390/ su3122323.

Hu Y, Hall CAS, Wang J, Feng L, Poisson A. Energy return on investment (EROI) of China's conventional fossil fuels: historical and future trends. Energy. 2013;54:352-64. https://doi.org/ 10.1016/j.energy.2013.01.067.

Intergovernmental Panel of Climate Change (IPCC). Climate change 2007: the physical science basis: contribution of Working Group I to the Fourth Assessment Report of the Intergovernmental Panel on Climate Change. Cambridge: Cambridge University Press; 2007.

Kittner N, Gheewala SH, Kammen DM. Energy return on investment (EROI) of mini-hydro and solar PV systems designed for a minigrid. Renew Energy. 2016;99:410-9. https://doi.org/10.1016/j. renene.2016.07.023.

Kong Y, Dong XC, Xu B, Li R, Yin Q, Song CF. EROI analysis for direct coal liquefaction without and with CCS: the case of the Shenhua DCL project in China. Energies. 2015a;8:786-807. https://doi.org/10.3390/en8020786. 
Kong Z, Dong X, Zhou Z. Seasonal imbalances in natural gas imports in major northeast Asian countries: variations, reasons, outlooks and countermeasures. Sustainability. 2015b;7:1690-711. https:// doi.org/10.3390/su7021690.

Kong ZY, Dong XC, Liu GX. Coal-based synthetic natural gas vs. imported natural gas in China: a net energy perspective. J Clean Prod. 2016a;131:690-701. https://doi.org/10.1016/j.jclepro. 2016.04.111.

Kong ZY, Dong XC, Shao Q, Wan X, Tang DL, Liu GX. The potential of domestic production and imports of oil and gas in China: an energy return on investment perspective. Pet Sci. 2016b;13:788-804. https://doi.org/10.1007/s12182-016-0120-7.

Lave R, Lutz B. Hydraulic fracturing: a critical physical geography review. Geogr Compass. 2014;8:739-54. https://doi.org/10. 1111/gec3.12162.

Li B, Fan CH, Zhang H, Chen ZZ, Sun LY, Xiong ZQ. Combined effects of nitrogen fertilization and biochar on the net global warming potential, greenhouse gas intensity and net ecosystem economic budget in intensive vegetable agriculture in southeastern China. Atmos Environ. 2015;100:10-9. https://doi.org/10. 1016/j.atmosenv.2014.10.034.

Li H, Yang S, Zhang J, Kraslawski A, Qian Y. Analysis of rationality of coal-based synthetic natural gas (SNG) production in China. Energy Policy. 2014;71:180-8. https://doi.org/10.1016/j.enpol. 2014.04.018.

Li MZ, Sun HS. The forecast methods for CBM recovery rate. Nat Gas Ind. 2008;28:25-9 (in Chinese).

Li Y. The ground transport technology of coalbed gas field. Master's thesis. Southwest Petroleum University, Chengdu, China, 2015. (in Chinese).

Lin BQ, Wang T. Forecasting natural gas supply in China: production peak and import trends. Energy Policy. 2012;49:225-33. https:// doi.org/10.1016/j.enpol.2012.05.074.

Lin W, Zhang N, Gu A. LNG (liquefied natural gas): a necessary part in China's future energy infrastructure. Energy. 2010;35:4383-91. https://doi.org/10.1016/j.energy.2009.04.036.

Luo DK, Chu WT, Wu XD, Li WC. Analysis on economic benefits of coalbed methane drilling technologies. Pet Explor Dev. 2009;36:403-7 (in Chinese).

Luo DK, Dai YJ, Xia LY. Economic evaluation based policy analysis for coalbed methane industry in China. Energy. 2011;36:360-8. https://doi.org/10.1016/j.energy.2010.10.031.

Luo PY. A discussion on how to significantly improve the single-well productivity of CBM gas wells in China. Nat Gas Ind. 2013;33:1-6 (in Chinese).

Manning P. What the frack? Everything you need to know about coal seam gas. Sydney: University of New South Wales Press; 2012.

Millar GJ, Couperthwaite SJ, Moodliar CD. Strategies for the management and treatment of coal seam gas associated water. Renew Sustain Energy Rev. 2016;57:669-91. https://doi.org/10. 1016/j.rser.2015.12.087.

Mu F, Zhong W, Zhao X, Che C, Chen Y, Zhu J, et al. Strategies for the development of CBM gas industry in China. Nat Gas Ind B. 2015;2:383-9. https://doi.org/10.1016/j.ngib.2015.09.013.

Mu FY, Sun FJ, Wang YB, Zhao QB. Characteristics of preproduction performance and technical countermeasures in the coalbed methane gas field of Qinshui Basin. Nat Gas Ind. 2009;29:117-9 (in Chinese).

Murphy DJ, Hall CAS, Dale M, Cleveland C. Order from chaos: a preliminary protocol for determining the EROI of fuels. Sustainability. 2011;3:1888-907. https://doi.org/10.3390/ su3101888.

Ou XM, Yan XY, Zhang XL. Life-cycle energy consumption and greenhouse gas emissions for electricity generation and supply in China. Appl Energy. 2011;88:289-97. https://doi.org/10.1016/j. apenergy.2010.05.010.
Peng JP, Lu L, Yang HX. Review on life cycle assessment of energy payback and greenhouse gas emission of solar photovoltaic systems. Renew Sustain Energy Rev. 2013;19:255-74. https:// doi.org/10.1016/j.rser.2012.11.035.

Pi GL, Dong XC, Dong C, Guo J, Ma ZW. The status, obstacles and policy recommendations of shale gas development in China. Sustainability. 2015;7:2353-72. https://doi.org/10.3390/ su7032353.

Qiao L, Shen RC, Huang HC, Wang KL, Xian BA. Low-cost drilling and completion techniques for coalbed methane in the southern Qinshui Basin, Central China. Pet Explor Dev. 2008;35:482-6 (in Chinese).

Qing YT. Research on fiscal and taxation policies for promoting the development of coalbed methane in China-take Shanxi Province as an example. Beijing Jiaotong University. Master's thesis, Beijing, China, 2016. (in Chinese).

Ren S. The steady-state simulation of the long-distance gas pipeline compressor station. Master's thesis. Southwest Petroleum University, Chengdu, China, 2015a. (in Chinese).

Ren S. Optimization technology of trunkline steady-state operation with compressors. Master's thesis. Southwest Petroleum University, Chengdu, China, 2015b. (in Chinese).

Shen ZH. Development trend of the modern drilling technology. Pet Explor Dev. 2005;32:89-91 (in Chinese).

Skone T, Littlefield J. The environmental impact of CBM. http:// www.worldcoal.com/documents/NETL-Skone-CBMReview.pdf (2013). Accessed 31 Mar 2016.

Su XD, Ge XH, Zhang Y, Qin Y. Analysis on greenhouse gas emissions of lifecycle for automobile fuel of coalbed methane. China Environ Prot Ind. 2015;8:25-9 (in Chinese).

Sun C. Energy efficiency analysis for unconventional natural gas development in China and evaluation of non-pipeline natural gas transportation options. Master's thesis. South China University of Technology, Guangzhou, China, 2015. (in Chinese).

Tait DR, Santos IR, Maher DT, Cyronak TJ, Davis RJ. Enrichment of radon and carbon dioxide in the open atmosphere of an Australian coal seam gas field. Environ Sci Technol. 2013;47:3099-104. https://doi.org/10.1021/es304538g.

Tan ZT, Wang SL, Ma L. Current status and prospect of development and utilization of coal mine methane in China. Energy Procedia. 2011;5:1874-7. https://doi.org/10.1016/j.egypro.2011.03.320.

Tao Y, Wang HX, Zheng X, Tian W, Liu H. Optimizing and practice of ground engineering construction in the Qinshui Basin CBM field. Gas Heat. 2015;35:28-34 (in Chinese).

Turton DJ. Lawyers in Australia's coal seam gas debate: a study of participation in recorded community forums. Extr Ind Soc. 2015;2:802-12. https://doi.org/10.1016/j.exis.2015.06.010.

U.S. Department of Energy. Life cycle GHG perspective report on exporting liquefied natural gas from the United States. http:// www.energy.gov/sites/prod/files/2014/05/f16/Life\%20Cycle\% 20GHG\%20Perspective\%20Report.pdf (2014). Accessed 31 Mar 2016.

United States Environmental Protection Agency (USEPA). Natural gas star international. https://www.epa.gov/natural-gas-star-pro gram/natural-gas-star-international (2016). Accessed 31 Mar 2016.

Wang HY, Li JM, Liu HL, Li GZ, Li J. Progress of basic theory and accumulation law and development technology of coal-bed methane. Pet Explor Dev. 2004;31:14-6 (in Chinese).

Wang JL, Feng LY, Zhao L, Snowden S. China's natural gas: resources, production and its impacts. Energy Policy. 2013;55:690-8. https://doi.org/10.1016/j.enpol.2012.12.034.

Wang R, Dong F, Meng ZP, Shuai Z. The controlling mechanism of geological structures on the production of coalbed methane wells in the Fanzhuang block. J China Univ Min Technol. 
2014;43:1026-30. https://doi.org/10.13247/j.cnki.jcumt.000112 (in Chinese).

Weißbach D, Ruprecht G, Huke A, Czerski K, Gottlieb S, Hussein A. Energy intensities, EROIs (energy returned on invested), and energy payback times of electricity generating power plants. Energy. 2013;52:210-21. https://doi.org/10.1016/j.energy.2013. 01.029.

Wu Y, Liu JS, Chen ZW, Elsworth D, Pone D. A dual poroelastic model for $\mathrm{CO}_{2}$-enhanced coalbed methane recovery. Int $\mathrm{J}$ Coal Geol. 2011;86:177-89. https://doi.org/10.1016/j.coal.2011.01. 004.

Xiahuanet. The room temperature of public buildings was controlled in Beijing, and the gas for heating is limited temporarily (in Chinese). http://news.xinhuanet.com/politics/2015-12/26/c_ 128569977.htm (2015). Accessed 31 Mar 2016.

Xu B, Feng LY, Wei WX, Hu Y, Wang JL. A preliminary forecast of the production status of China's Daqing oil field from the perspective of EROI. Sustainability. 2014;6:8262-82. https://doi. org/10.3390/su6118262.

Xu GC, Liu X, Wang QS, Yu XC, Hang YH. Integrated rice-duck farming mitigates the global warming potential in rice season. Sci Total Environ. 2016;575:58-66. https://doi.org/10.1016/j. scitotenv.2016.09.233.

Xue G, Xu Q, Wang HX, Wang YD, Liu ZB. Current situation and analysis on CBM Surface gathering and transportation system in China. China Coalbed Methane. 2011;8:40-3 (in Chinese).

Yang M. Climate change and energy policies, coal and coalmine methane in China. Energy Policy. 2009;37:2858-69. https://doi. org/10.1016/j.enpol.2009.02.048.
Yang S. Study on forecasting methods of economic peak production of a coalbed methane well. Master's thesis. China University of Petroleum, Beijing, China, 2008. (in Chinese).

Yang S, Kang YS, Zhao Q, Wang HY, Li JM. Method for predicting economic peak yield for a single well of coalbed methane. J China Univ Min Technol. 2008;18:521-6.

Yousefi M, Damghani AM, Khoramivafa M. Energy consumption, greenhouse gas emissions and assessment of sustainability index in corn agroecosystems of Iran. Sci Total Environ. 2014;493:330-5. https://doi.org/10.1016/j.scitotenv.2014.06. 004.

Zeng M, Ouyang SJ, Zhang YJ, Shi H. CCS technology development in China: status, problems and counter measures-based on SWOT analysis. Renew Sustain Energy Rev. 2014;39:604-16. https://doi.org/10.1016/j.rser.2014.07.037.

Zhang B, Chen GQ, Li JS, Tao L. Methane emissions of energy activities in China 1980-2007. Renew Sustain Energy Rev. 2014;29:11-21. https://doi.org/10.1016/j.rser.2013.08.060.

Zhang Q, Li Z, Wang G, Li HL. Study on the impacts of natural gas supply cost on gas flow and infrastructure deployment in China. Appl Energy. 2016;162:1385-98. https://doi.org/10.1016/j.ape nergy.2015.06.058.

Zhou SZ, Zhang WZ. The current methods for estimating recovery rate of CBM and the existing problems in China. China Coalbed Methane. 2011;8:10-2 (in Chinese). 